\title{
Angiotensin II receptor blockers induce autophagy in prostate cancer cells
}

\author{
YUNSEO WOO and YU-JIN JUNG \\ Department of Biological Sciences and Bio-Information Technology Medical Convergence Program, \\ Kangwon National University, Chuncheon, Gangwon 200-701, Republic of Korea
}

Received January 20, 2016; Accepted January 26, 2017

DOI: $10.3892 / 01.2017 .5872$

\begin{abstract}
Angiotensin II receptor blockers (ARBs) are anti-hypertensive drugs that competitively inhibit the binding of angiotensin II to its receptor, resulting in blood vessel dilation and the reduction of blood pressure. These antagonists are also known as sartans, and are a group of pharmaceuticals that possess tetrazole or imidazole groups. In the present study, the anticancer and antimetastatic effects of the ARBs fimasartan, losartan, eprosartan and valsartan on the human prostate cancer PC-3, DU-145 and LNCap-LN3 cell lines were investigated in vitro. The proliferation of the prostate cancer cells was inhibited following treatment with $100 \mu \mathrm{M}$ ARB. In particular, treatment with fimasartan resulted in marked anti-proliferative activity compared with the other ARBs. With respect to the molecular mechanism of the growth inhibition exhibited by the ARBs, 3-methyladenin (3-MA), an autophagy inhibitor, was revealed to increase the survival rate of PC-3 cells when cell death inhibitors were pretreated with fimasartan. In addition, the ARBs induced autophagy with increased expression levels of autophagy protein (Atg) 5-12, Atg 16-like-1, beclin-1 and microtubule-associated protein 1A/1B-light chain 3 (LC3). Notably, the enhanced expression of LC3-II (a 6.7-fold increase at $72 \mathrm{~h}$ ) was observed in PC3 cells treated with fimasartan. This was supported by the observation of the time-dependent accumulation of LC3-positive foci in PC-3. In addition, a migration assay indicated that the ARBs induced anti-metastatic effects in PC-3 and DU-145 cells. The aforementioned results suggest that ARBs may induce autophagy-associated cell death and anti-metastatic activity in prostate cancer cells. Thus, ARBs may be a potential medication for patients with prostate cancer and hypertension.
\end{abstract}

Correspondence to: Dr Yu-Jin Jung, Department of Biological Sciences and Bio-Information Technology Medical Convergence Program, Kangwon National University, 1 Gangwondaehak-gil, Chuncheon, Gangwon 200-701, Republic of Korea

E-mail: yjjung@kangwon.ac.kr

Key words: angiotensin II receptor blockers, prostate cancer, autophagy, anti-cancer, anti-metastatic

\section{Introduction}

As the average life span has increased with the advancement of medicine, there has been an increase in the proportion of elderly people in the population worldwide (1). Despite advances in medical technology, the number of elderly people with cancer has increased, and this population is difficult to treat (2). In addition, elderly people exhibit an elevated incidence of high blood pressure (3), and numerous studies have reported that hypertension is associated with cancer (4-8). For anticancer therapy in this population, angiotensin receptor II blockers (ARBs) are currently being investigated (9-11).

Angiotensin II is the activated form of the protein angiotensin, resulting from the cleavage of angiotensin I by angiotensin-converting enzyme, and promotes the reabsorption of water and sodium ions and the contraction of blood vessels, thereby reducing blood pressure (12). Therefore, the blood pressure of patients with hypertension can be reduced by targeting angiotensin receptor II (13). Angiotensin II receptor antagonists, also known as sartans, are a group of pharmaceuticals that possess tetrazole or imidazole groups, which function as anti-hypertensive drugs (14). Previous studies have indicated that angiotensin II promotes the proliferation and metastasis of tumors $(15,16)$, and that ARBs exhibit antiproliferative and antimetastatic effects on tumors (17-20). In addition, it has been reported that ARBs inhibit the growth of prostate cancer cell lines via suppression of the mitogen-activated protein kinase (MAPK) or signal transducer and activator of transcription 3 (STAT3) phosphorylation (21) and exhibited an antitumor effect on patients with prostate cancer (22-24).

The ultimate aim of cancer therapy is the death of cancer cells, which may be induced by apoptotic or necrotic pathways $(25,26)$. However, cancer cells are able to evade cell death mechanisms (27), therefore a novel approach to target anti-apoptotic mechanisms in cancer is required. Previous reports have indicated that the induction of autophagic signals led to the death of cancer cells, despite autophagy being used as a survival strategy in cells experiencing insufficient supply of nutrients under hypoxic conditions (28-30). The phenomenon is termed autophagy-induced cell death, and is an alternative therapeutic approach to apoptosis-resistant cancer cells.

In the present study, the dose- and time-dependent anticancer effects of commercially available ARBs, and whether the ARBs were able to induce autophagy-induced cell death, 
were investigated in prostate cancer cells. Furthermore, the inhibitory effect of the ARBs with respect to the migration and proliferation of tumor cells was investigated.

\section{Materials and methods}

Reagents. Fimasartan was obtained from Boryung Pharmaceutical Co., Ltd. (Seoul, Korea). Losartan potassium (Merck Sharp \& Dohme,Hoddesdon, UK), eprosartan mesylate (Solvay Pharmaceuticals, Weesp, Netherlands) and valsartan (Novartis AG, Basel, Switzerland) were used in the present study. All ARBs were used at concentrations of 100, 200 and $400 \mu \mathrm{M}$. The inhibitors 3-methyladenine (3-MA; Sigma-Aldrich; Merck KGaA, Darmstadt, Germany), Z-VAD-FMK (Calbiochem, Billerica, MA, USA), a pan-caspase inhibitor, and Necrostatin-1 (Sigma-Aldrich, St Louis, MO, USA) were used to treat the human cancer cell lines to inhibit each type of cell death.

Cell lines and cell culture. The human prostate cancer cell lines PC3 [Korean Cell Line Bank (KCLB) no. 21435], DU145 (KCLB no. 30081) and LNCap-LN3 (KCLB no. 80018) were obtained from the KCLB (Seoul, Korea). A total of $3 \times 10^{5}$ of each type of prostate cancer cell was plated in $60-\mathrm{mm}$ cell culture dishes (SPL Life Sciences, Pocheon, Korea). Cells were grown in RPMI-1640 medium (GE Healthcare Life Sciences, Logan, UT, USA) and supplemented with $10 \%$ heat inactivated fetal bovine serum (FBS; Lonza Group Ltd., Walkersville, MD, USA) and antibiotics $(1,000 \mathrm{U} / \mathrm{ml}$ penicillin and $1,000 \mu \mathrm{g} / \mathrm{ml}$ streptomycin; both GE Healthcare Life Sciences). The FBS was heat inactivated for $1 \mathrm{~h}$ at $56^{\circ} \mathrm{C}$. The prostate cancer cells were cultured at $37^{\circ} \mathrm{C}$, in a humidified atmosphere containing $5 \% \mathrm{CO}_{2}$. To verify the mechanisms of cell death with treatment of ARBs, PC-3 cells were pretreated with $10 \mathrm{mM} 3-\mathrm{MA}$, $50 \mu \mathrm{M}$ Z-VAD-FMK or $50 \mu \mathrm{M}$ Necrostatin- 1 or $3 \mathrm{~h}$ at $37^{\circ} \mathrm{C}$ prior to fimasartan treatment at a concentration of $200 \mu \mathrm{M}$.

Proteinextraction andwestern blotting. The prostate cancercell lines $\left(3 \times 10^{5}\right.$ cells per cell line) were treated with $200 \mu \mathrm{M}$ ARBs for $0,24,48,72$ and $96 \mathrm{~h}$ at $37^{\circ} \mathrm{C}$ under $5 \% \mathrm{CO}_{2}$. The cells were then harvested and the proteins were extracted, using radioimmunoprecipitation assay buffer containing $10 \mathrm{mM}$ Tris- $\mathrm{HCl}$, $1 \mathrm{mM}$ EDTA, $140 \mathrm{mM} \mathrm{NaCl}, 0.1 \%$ deoxycholate, $0.1 \%$ SDS, $100 \%$ Triton X-100 and 100X Protease Inhibitor Cocktail Set I (EMD Millipore, Billerica, MA, USA). The protein samples of the cell lysates were quantified using a Bradford assay. In total, $30 \mu \mathrm{g}$ of each protein samples loaded onto the gel. Each sample was separated by 10-15\% SDS-PAGE and transferred onto a $0.45 \mu \mathrm{m}$ polyvinylidene fluoride membrane (Millipore, Billerica, MA, USA) for $2 \mathrm{~h}$ at 100 constant voltage on ice. The membranes were blocked with 5\% skimmed milk in TBS-T (TBS and Tween-20) buffer for $1 \mathrm{~h}$ at room temperature. The primary antibodies used were anti-LC3B (cat. no. 2775; Cell Signaling Technology, Inc., Danvers, MA, USA), anti-Atg12 (cat. no. 4180; Cell Signaling Technology, Inc.), anti-Atg16L1 (cat. no. 8089; Cell Signaling Technology, Inc.), anti-Beclin-1 (cat. no. 3738; Cell Signaling Technology, Inc.) and anti- $\beta$-actin (cat. no. sc-130656; Santa Cruz Biotechnology, Inc., Dallas, TX, USA). Anti-rabbit IgG (cat. no. 7074; Cell Signaling Technology, Boston, MA, USA) was used as the secondary antibody. All antibodies were diluted 1,000-fold with blocking buffer. Membranes were incubated with primary antibodies for $3.5 \mathrm{~h}$ and with secondary antibody for $2.5 \mathrm{~h}$ at room temperature. The membranes were washed 3 times in TBS-T buffer for $10 \mathrm{~min}$. The membranes were developed using an enhanced chemiluminescence western blotting detection system (BD Biosciences, San Hose, CA, USA) according to the protocol of the manufacturer, and exposed to X-ray sheets (Agfa-Gevaert N.V., Mortsel, Belgium). The western blotting results were quantified using densitometry (ImageJ; version 1.48; National Institutes of Health, Bethesda, MD, USA).

Cell proliferation assay. Cell viability in the presence or absence of the ARBs was determined using a Premix WST-1 Cell Proliferation Assay System (Takara Bio, Inc., Otsu, Japan). In total, $1 \times 10^{3}$ cells (100 $\mu 1 /$ well) were incubated in 96-well plates for $24 \mathrm{~h}$ at $37^{\circ} \mathrm{C}$ under $5 \% \mathrm{CO}_{2}$. Subsequently, 100, 200 and $400 \mu \mathrm{M}$ ARBs in RPMI-1640 were added to the wells and cultured at $37^{\circ} \mathrm{C}$ for 48 and $72 \mathrm{~h}$ for PC 3 and DU145 cells, and 60 and $120 \mathrm{~h}$ for LNCap-LN3 cells. A total of $10 \mu \mathrm{l}$ WST-1 solution was added to each well, and the plates were incubated for $30 \mathrm{~min}$ at $37^{\circ} \mathrm{C}$, following which the absorbance at 450 and $690 \mathrm{~nm}$ was measured using a microplate reader.

Confocal microscopy. The PC3 human prostate cancer cells were seeded onto glass coverslips (Paul Marienfeld $\mathrm{GmbH}$ \& Co., KG, Lauda-Königshofen, Germany) at a density of $1 \times 10^{5}$ cells/well in 6-well plates for $24 \mathrm{~h}$, and were treated with fimasartan $(200 \mu \mathrm{M})$ for 24,48 and $72 \mathrm{~h}$ at $37^{\circ} \mathrm{C}$ under $5 \% \mathrm{CO}_{2}$. Following all treatment and incubation, the cells were fixed with $4 \%$ formaldehyde at room temperature for $15 \mathrm{~min}$. The cells were permeabilized with $0.2 \%$ Triton X-100 in PBS for 15-20 min, then blocked with $1 \%$ bovine serum albumin (BSA; Sigma-Aldrich; Merck KGaA) in PBS solution for $1 \mathrm{~h}$ at room temperature. On the basis of a previous study (30), PC3 cells was incubated with anti-LC3 antibody (cat. no. PM036; Medical \& Biological Laboratories Co., Ltd., Nagoya, Japan; 1:500 dilution in 1\% BSA and 0.05\% Triton X-100 in PBS) for $2 \mathrm{~h}$ at room temperature. Subsequent to washing with PBS, cells were treated with anti-rabbit-fluorescein isothiocyanate (cat. no. 111-095-003; Jackson ImmunoResearch Laboratories, Inc., West Grove, PA, USA; 1:500 dilution in 1\% BSA, 0.05\% Triton X-100 in PBS) for $2 \mathrm{~h}$ at room temperature. Each well was washed twice with $0.02 \%$ Tween- 20 and $1 \%$ BSA in PBS. The coverslips were mounted and the cells were examined using confocal microscopy (FV1000; Olympus Corporation, Tokyo, Japan). The results were quantified by densitometry.

Migration assay. A Transwell (6.5 $\mu \mathrm{m}$ pore; Corning Incorporated, Corning, NY, USA) migration assay was performed. Top chambers were seeded with $100 \mu 1$ RPMI-1640 containing PC 3 and DU145 cells ( $1 \times 10^{4}$ cells per well) and the bottom chambers were filled with $600 \mu 1 \mathrm{RPMI}-1640$, and the chambers were incubated for $24 \mathrm{~h}$ at $37^{\circ} \mathrm{C}$ under $5 \% \mathrm{CO}_{2}$. After $24 \mathrm{~h}$, the bottom chamber was washed with $1 \times \mathrm{xBS}$ and was filled with $600 \mu \mathrm{l}$ RPMI-1640 with or without $200 \mu \mathrm{M}$ fimasartan for $6 \mathrm{~h}$ at $37^{\circ} \mathrm{C}$. Migrated cells on the bottom side of the membrane were fixed with $4 \%$ paraformaldehyde for $30 \mathrm{~min}$ at room temperature and washed with PBS twice. Cell migration was evaluated through hematoxylin and eosin staining. 
The results were measured as the mean number of migrated cells counted using a Motic AE31 optical microscope (Motic, Xiamen, China). Data are expressed as the mean \pm standard deviation from 3 independent experiments.

Statistical analysis. All data are presented as the mean \pm the standard deviation. Statistical analysis was performed with one-way analysis of variance followed by a Tukey-Kramer multiple comparison test by GraphPad Prism (version 5.0; GraphPad Software, Inc., La Jolla, CA, USA). P<0.05 was considered to indicate a statistically significant difference. Experiments were repeated a minimum of 3 times for each condition.

\section{Results}

Reduced cell viability in ARB-treated prostate cancer cell lines. The expression of angiotensin II receptor has been reported in the human prostate cancer cell lines PC3, DU145 and LNCap-LN3 (31). Therefore, the anti-proliferative effects of the ARBs fimasartan, losartar, eprosartan and valsartan were investigated in human prostate cancer cells in the present study (Fig. 1). The ARBs at concentrations 100, 200 and $400 \mu \mathrm{M}$ were applied to PC3, DU145 and LNCap-LN3 cells, and the cytotoxicity of the ARBs was evaluated by a WST-1 assay. Considering the difference in the doubling time of the cells (PC3, 35 h; DU145, 29 h; and LNCap-LN3, 60 h), cell proliferation was measured at 48 and $72 \mathrm{~h}$ in the PC3 and DU145 cells, and at 60 and $120 \mathrm{~h}$ in the LNCap-LN3 cells. Compared with the control group, the ARB-treated cells showed reduced cell viability. At $400 \mu \mathrm{M}$ all the ARBs exerted anti-proliferative effects on prostate cancer cells at each time point, but fimasartan exhibited the greatest cytotoxicity (Fig. 1). Valsartan demonstrated the lowest anti-proliferative activity compared with other ARBs in the prostate cancer cells. LNCap-LN3 had the longest doubling time of the cells investigated, and demonstrated similar cytotoxic effects in response to ARBs to the other cells (Fig. 1C) The present results are consistent with previous studies in which ARBs were demonstrated to inhibit the growth of bladder, breast and gastric cancer (17-20), and fimasartan was observed to exert the greatest anti-proliferative effect on prostate cancer cells.

Autophagy-induced cell death in ARB-treated PC3 cells. To verify the type of cell death mechanism involved in prostate cancer cells following ARB treatment, specific inhibitors that block each type of cell death were administered to PC-3 cells with fimasartan. Although pan-caspase inhibitor, an apoptosis blocker, slightly reduced ARB-induced cell death at $48 \mathrm{~h}$, the cell survival fraction was restored significantly when the cells were treated with 3-MA, an autophagy inhibitor, at 72 h. Necrostatin-1, a necrosis inhibitor, did not significantly increase the cell viability in fimasartan-treated PC-3 cells. Autophagy-induced cell death, also known as type II programmed cell death, was proposed by Schweichel and Merker (32); it is a cellular suicide process accompanied by the appearance of a giant cytoplasmic vacuole known as the autophagosome. This process may be induced in cancer cells that are resistant to apoptosis due to a deficiency in apoptosis-associated proteins, including B-cell lymphoma-2-like protein 4 and B-cell lymphoma- 2 homologous antagonist/killer.
Additionally, the inhibition of caspases, which are key apoptosis-associated proteins, is able to prevent cell death (33). Therefore, the induction of autophagic cell death is an alternative death mechanism in apoptosis-resistant cells. LC3, the mammalian homologue of yeast Atg8, is a marker of autophagosome formation. When autophagic signals are activated, a phagophore is formed and LC3-I is conjugated to phosphatidylethanolamine, forming LC3-II, which, with the Atg12-Atg5-Atg16 complex, serves an important role in phagophore elongation. Therefore, the detection of LC3, the Atg12-5 complex, Atg16 and Beclin-1 using western blotting provides suitable markers by which to measure the signaling initiation of autophagy. The PC3 cells were treated with $200 \mu \mathrm{M}$ fimasartan, and harvested at $0,24,48,72$ and $96 \mathrm{~h}$, following which western blotting was performed. This indicated changes in the expression levels of autophagy-associated proteins, with the peak level of LC3-II expression induced at 72 h (6.7-fold increase; Fig. 2B). The inhibitor 3-MA reduced the expression level of converted LC3-II in fimasartan-treated cells (Fig. 2C). In addition, numerous vacuolar compartments were observed in the PC-3 cells subsequent to treatment with fimasartan at $72 \mathrm{~h}$ (Fig. 2C). Therefore, fimasartan may be regarded as an autophagy inducer in PC3 human prostate cancer cells. Additionally, treatment with $200 \mu \mathrm{M}$ losartan, eprosartan and valsartan resulted in alterations in the expression of autophagy-associated proteins in PC3 cells, similar to the result following fimasartan treatment (Fig. 2D). Losartan and eprosartan induced peak levels of LC3-II at $96 \mathrm{~h}$ (18.8and 11.1-fold increases, respectively), and valsartan treatment resulted in the largest increase in the expression of LC3-II at $72 \mathrm{~h}$ (11.2-fold increase), measured using densitometry.

To evaluate whether autophagy was occurring in the PC3 cells following treatment with fimasartan, confocal imaging of immunofluorescent staining was performed. LC3-positive foci were observed scattered throughout the cytoplasm following fimasartan treatment (Fig. 3A). Furthermore, the number of LC3-positive foci increased and the intensity of fluorescein isothiocyanate-fluorescence was enhanced in a time-dependent manner. The results were quantified by measuring the number of cells containing LC3-positive foci compared with the total number of cells (Fig. 3B). Therefore, it appears that ARBs are able to induce autophagy and initiate growth inhibition in human prostate cancer cell lines.

Anti-migratory effect of ARBs. A measurement of the potential of a compound to be used as an anti-cancer agent is whether it exerts anti-migratory effects on cancer cells. Therefore, an experiment was designed to verify anti-migratory activity in PC3 and DU145 cells, using a Transwell assay, to investigate whether fimasartan exerts a suppressive effect on tumor metastasis. The results indicated that treatment with $200 \mu \mathrm{M}$ fimasartan induced anti-migratory activity in PC3 and DU145 cells (0.88- and 0.90-fold increase, respectively; Fig. 4). Thus, fimasartan may possess the potential to be used as an anti-cancer agent for hypertensive patients with prostate cancer.

\section{Discussion}

Multiple signaling pathways are activated in cells stimulated by angiotensin II, including the Janus kinase/signal transducer 

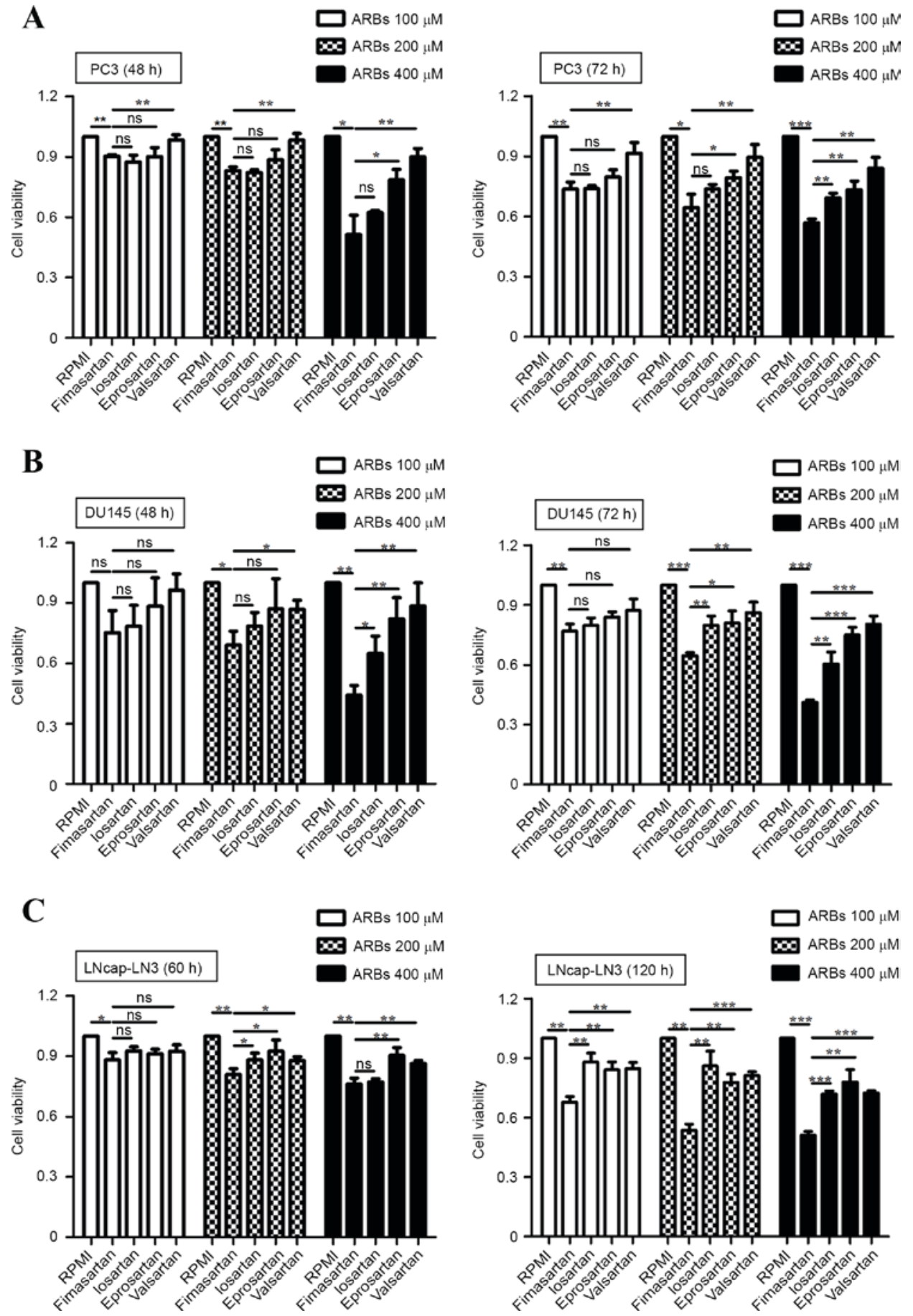

Figure 1. Analysis of cell proliferation following treatment of prostate cancer cell lines with ARBs. A WST-1 assay was conducted to analyze cell viability. Cell viability was measured at 48 and $72 \mathrm{~h}$ in (A) PC3 and (B) DU145 cells or at 60 and $120 \mathrm{~h}$ in (C) LNCap-LN3 cells. Data are expressed as the mean \pm standard deviation from 3 experiments with 3 replicates each. ${ }^{*} \mathrm{P}<0.05,{ }^{* *} \mathrm{P}<0.01,{ }^{* * *} \mathrm{P}<0.001$. ARB, angiotensin II receptor blocker.

and activator of transcription Jak2/STAT, MAPK, phosphoinositide 3 kinase/protein kinase B Akt and extracellular growth factor signaling pathways, which may result in cell proliferation, migration and tubulogenesis (34). This suggests that the treatment of cancer cells with ARBs may inhibit the proliferation and migration of tumor cells. The present study indicated that ARBs induce autophagy in prostate cancer cells and may therefore be potential anti-cancer agents. In addition, the present study suggests that ARBs may be used as a therapeutic agent for patients with prostate cancer and hypertension. However, the present study was unable to ascertain whether autophagy is associated with the antiproliferation and antimigration effects of ARBs on prostate cancer cells. The induction of autophagy and inhibition of proliferation by a 5 '-adenosine monophospate-activated protein kinase inhibitor, compound $\mathrm{C}$, in human colorectal cancer cells has been reported (35). In addition, compound $\mathrm{C}$ has been reported to inhibit DNA-damage regulated autophagy modulator 1 and p62, autophagy-associated factors, and to regulate cell migration and invasion in glioblastoma (36). Furthermore, autophagy was induced in mice injected with mitoxantrone leading to an anticancer immune response (37). The aforementioned 

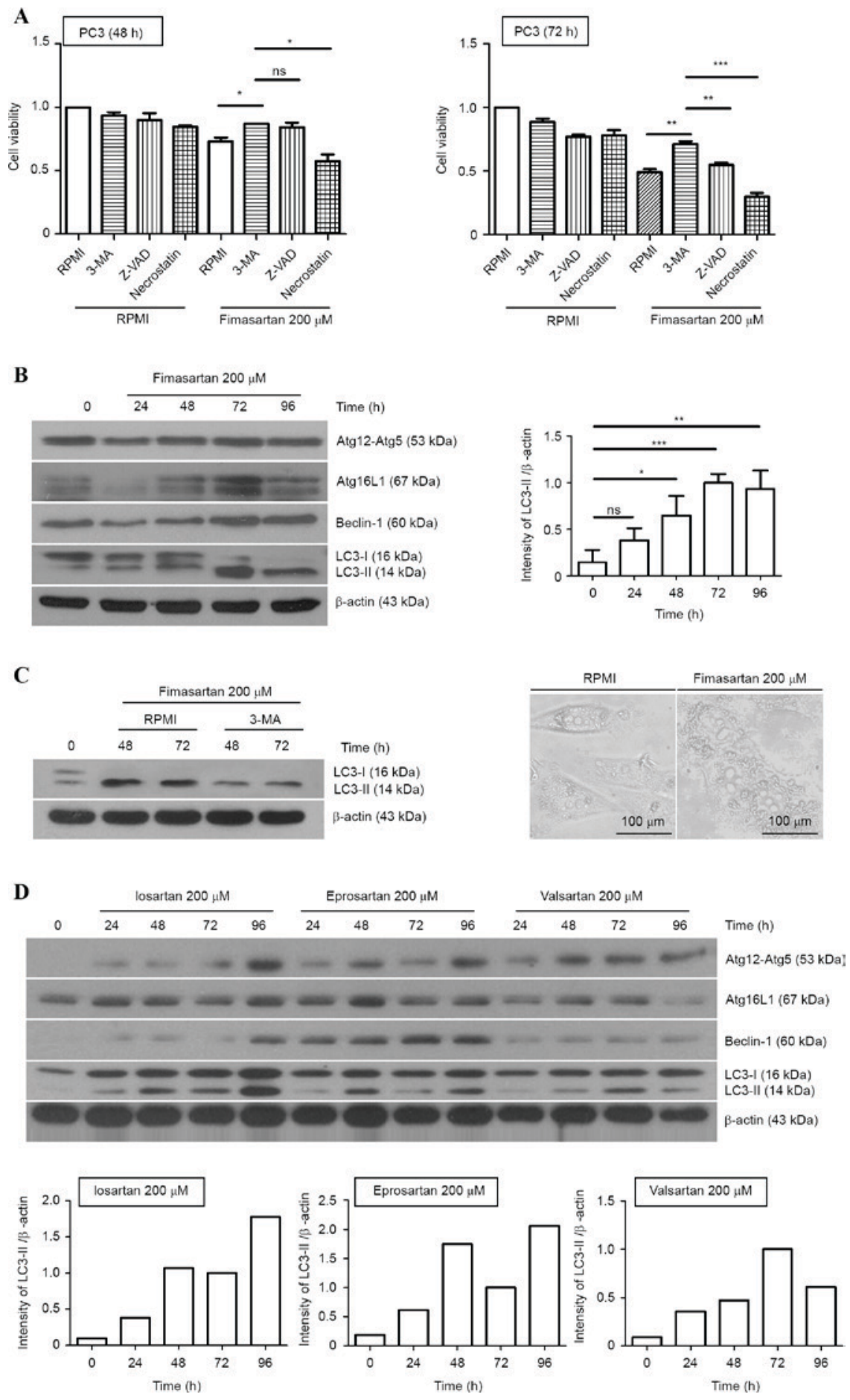

Figure 2. Autophagy-induced cell death in the angiotensin II receptor blocker-treated PC3 cells. (A) PC3 cells were pretreated with 3-MA (10 mM), Z-VAD-FMK $(50 \mu \mathrm{M})$ or Necrostatin-1 $(50 \mu \mathrm{M})$ for $3 \mathrm{~h}$. Each group of cells was stimulated by fimasartan $(200 \mu \mathrm{M})$ and cell viability was analyzed for 48 and $72 \mathrm{~h}$ via WST-1 assay. (B) PC3 cells were treated with $200 \mu \mathrm{M}$ fimasartan, and changes in the expression levels of Atg-12-Atg5, Atg16L1, Beclin-1 and LC-3 were measured using western blot analysis at each time point. (C) The expression levels of LC3-II were significantly reduced with 3-MA pretreatment (left panel). PC 3 cells were observed at $72 \mathrm{~h}$ subsequent to $200 \mu \mathrm{M}$ fimasartan treatment under a microscope. (D) PC3 cells were treated with $200 \mu \mathrm{M}$ losartan, eprosartan or valsartan, and western blot analysis was performed to detect alterations in the expression of autophagy-associated proteins. Densitometry results are presented as the mean \pm standard deviation of triplicate experiments. $\beta$-actin was used as a loading control. ns, non-significant; ${ }^{*} \mathrm{P}<0.05,{ }^{* *} \mathrm{P}<0.01$, ${ }^{* * *} \mathrm{P}<0.001$. 3-MA, 3-methyladenine; Atg, autophagy protein; LC3, microtubule-associated protein 1A/1B-light chain 3.

studies suggest that ARBs may be potential antitumoral agents via alterations in the autophagic process. The results of the present study indicated that ARBs increased autophagy in prostate cancer cell lines, supported by the increased expression levels of autophagy-associated genes and observation of LC3-positive foci by confocal microscopy. In addition, fimasartan exhibited superior antitumor activity compared with losartan, eprosartan and valsartan. Low concentrations $(0.1,1$ and $10 \mu \mathrm{M})$ of ARBs did not exhibit antitumor effects in prostate cancer cells in a preliminary study (data not shown), therefore higher doses $(100,200$ and $400 \mu \mathrm{M})$ of ARBs were used in the present study. These concentrations were suitable 


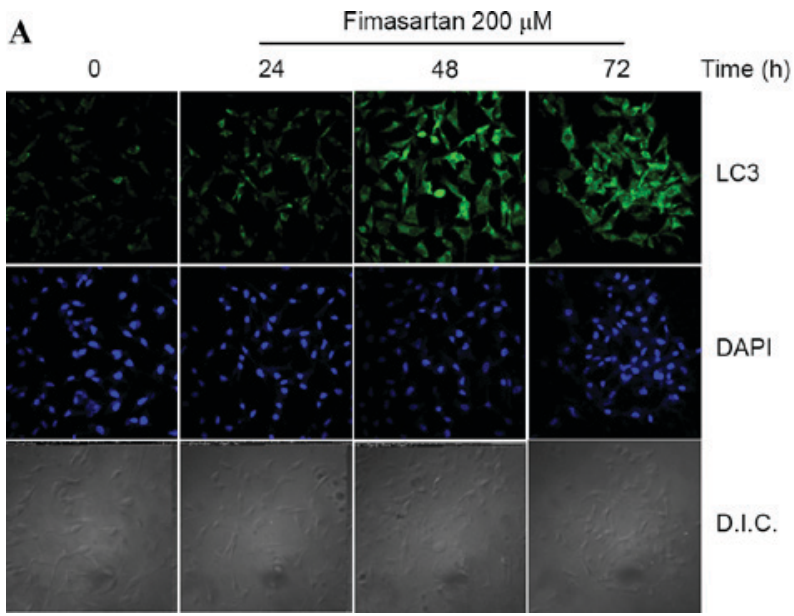

B

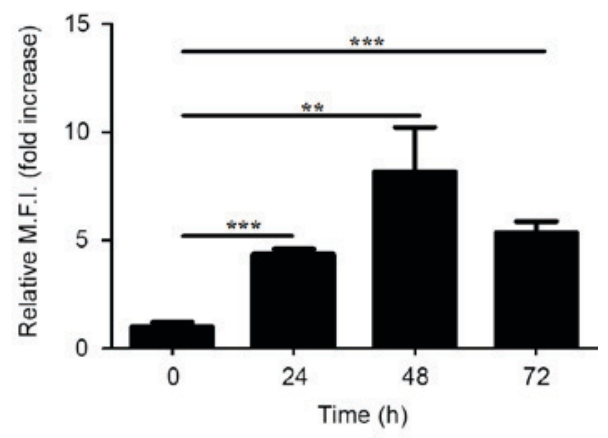

Figure 3. Formation of LC3-positive foci in the fimasartan-treated PC3 cells. (A) The PC3 cells were treated with $200 \mu \mathrm{M}$ fimasartan for 24,48 or $72 \mathrm{~h}$, and endogenous LC3 was detected using an immunofluorescence assay. Cells were stained with DAPI to visualize the nuclei (blue), and immunolabeled with the anti-LC3 antibody, with the addition of fluorescein isothiocyanate-conjugated IgG (green). (B) The quantification for the immunofluorescence images of 3 independent replicates. Values are presented as the mean \pm standard deviation. DAPI, 4,6'-diamidino-2-phenylindole; LC3, microtubule-associated protein 1A/1B-light chain 3; D.I.C, disseminated intravascular coagulation; M.F.I, mean fluorescent intensity; ${ }^{* *} \mathrm{P}<0.01,{ }^{* * * *} \mathrm{P}<0.001$.

A

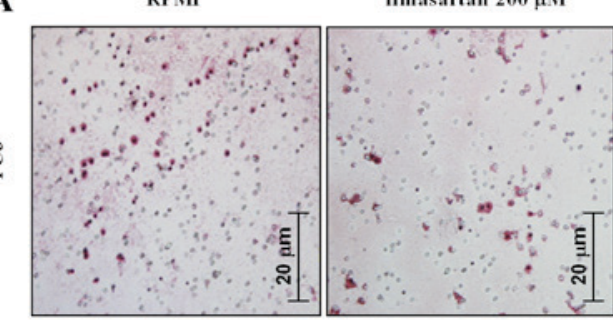

B

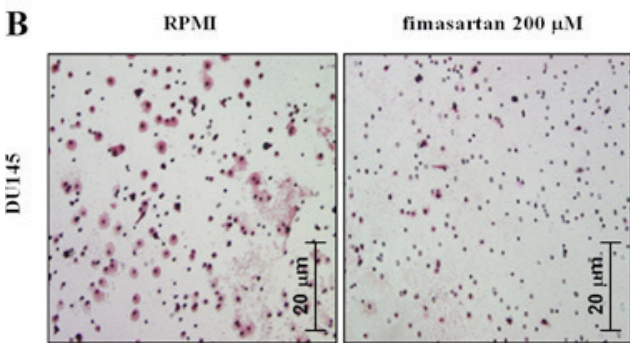

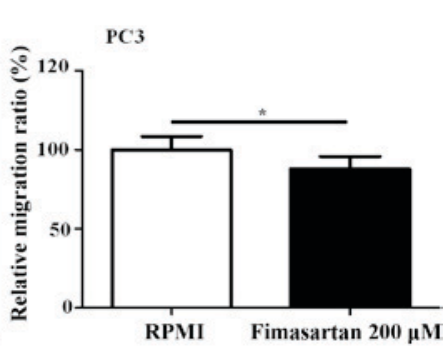

DU145

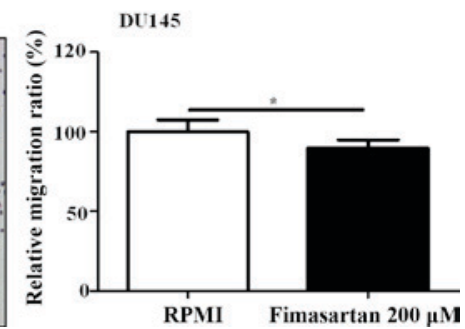

Figure 4. Results of the migration assay. A total of $1 \times 10^{4}$ (A) PC3 and (B) DU145 cells were seeded in 6-Transwell cell culture plates and treated with $200 \mu \mathrm{M}$ fimasartan. Following $6 \mathrm{~h}$ treatment, a migration assay was performed in addition to hematoxylin and eosin staining. Data are expressed as the mean \pm standard deviation from 3 independent experiments. ${ }^{*} \mathrm{P}<0.05$.

for investigation, as previous studies have not reported side effects in patients with hypertension prescribed similar high doses of ARBs $(38,39)$.

Considering the presence of other cells in the tumor microenvironment in addition to the tumor cells, the degree of influence of ARB treatment on cancer accessory cells, including immune cells, should be considered. During tumor formation, circulating monocytes infiltrate tumor tissue and polarize into tumor-associated macrophages that express beneficial factors for the tumor, including vascular endothelial growth factor and arginase 1 (40). Therefore, it is important to consider the effect of ARBs on the macrophages present within the tumor tissue. Angiotensin II is a key mediator of fibrosis in cardiac fibrosis, and enhances the infiltration of macrophages into tissues and the subsequent polarization of the cells into the M2 phenotype via serum-glucocorticoid-regulated kinase 1 (41). As ARBs exhibited potential in terms of weakening prostate cancer in clinical trials (22-24), it may be suggested that the polarizing of tumor-associated macrophages from monocytes may be inhibited by ARB treatment. Therefore, the results of this study indicate that ARBs possess the potential to be a novel therapeutic agent for patients with prostate cancer and high blood pressure, since ARBs induce autophagy and lead to anticancer effects in prostate cancer cells.

\section{Acknowledgements}

The present study was supported by a National Research Foundation of Korea grant funded by the Ministry of Education, Science and Technology (grant no. 2012R1A1A2006349) and Ministry of Science, ICT and Future Planning (grant nos. 2014M2B2A 9030381 and 2015M2B2A6028602). Funding was also provided by a 2015 (C1011746-01-01) and 2016 Research Grant from Kangwon National University. 


\section{References}

1. Daniels N: Global aging and the allocation of health care across the life span. Am J Bioeth 13: 1-2, 2013.

2. Orom H, Penner LA, West BT, Downs TM, Rayford W and Underwood W: Personality predicts prostate cancer treatment decision-making difficulty and satisfaction. Psychooncology 18: 290-299, 2009

3. Guxens M, Fitó M, Martínez-González MA, Salas-Salvadó J, Estruch R, Vinyoles E, Fiol M, Corella D, Arós F, Gómez-Gracia E, et al: Hypertensive status and lipoprotein oxidation in an elderly population at high cardiovascular risk. Am J Hypertens 22: 68-73, 2009.

4. Lin GM, Liu PY, Wu CF, Wang WB and Han CL: Carvedilol use and specific cancer risk in the population with hypertension. Int J Cardiol 186: 52-53, 2015.

5. Mouhayar E and Salahudeen A: Hypertension in cancer patients. Tex Heart Inst J 38: 263-265, 2011

6. Valcamonico F, Arcangeli G, Consoli F, Nonnis D, Grisanti S, Gatti E, Berruti A and Ferrari V: Idiopathic intracranial hypertension: A possible complication in the natural history of advanced prostate cancer. Int J Urol 21: 335-337, 2014

7. Tahover E, Uziely B, Salah A, Temper M, Peretz T and Hubert A: Hypertension as a predictive biomarker in bevacizumab treatment for colorectal cancer patients. Med Oncol 30: 327, 2013.

8. Pant S, Martin LK, Geyer S, Wei L, Van Loon K, Sommovilla N, Zalupski M,Iyer R, Fogelman D, Ko AH and Bekaii-Saab T: Treatment-related hypertension as a pharmacodynamic biomarker for the efficacy of bevacizumab in advanced pancreas cancer: A pooled analysis of 4 prospective trials of gemcitabine-based therapy with bevacizumab. Am J Clin Oncol 39: 614-618, 2016.

9. Zhang J, Liu J, Chen J, Li X, Wu Y, Chen H, Wu W, Zhang K and $\mathrm{Gu} \mathrm{L}$ : Angiotensin receptor blockers (ARBs) reduce the risk of lung cancer: A systematic review and meta-analysis. Int J Clin Exp Med 8: 12656-12660, 2015.

10. Chae YK, Valsecchi ME, Kim J, Bianchi AL, Khemasuwan D, Desai A and Tester W: Reduced risk of breast cancer recurrence in patients using ACE inhibitors, ARBs, and/or statins. Cancer Invest 29: 585-593, 2011.

11. Mann SJ and Christos PJ: ACE inhibitors and ARBs: Do they reduce the risk of cancer? J Clin Hypertens (Greenwich) 16: 6-7, 2014.

12. Sigmund CD: Structural biology: On stress and pressure. Nature 468: 46-47, 2010.

13. Asmar R: Targeting effective blood pressure control with angiotensin receptor blockers. Int J Clin Pract 60: 315-320, 2006

14. van Zwieten PA: Angiotensin II receptor antagonists (AT1-blockers, ARBs, sartans): Similarities and differences. Neth Heart J 14: 381-387, 2006.

15. Imai N, Hashimoto T, Kihara M, Yoshida S, Kawana I, Yazawa T, Kitamura $\mathrm{H}$ and Umemura S: Roles for host and tumor angiotensin II type 1 receptor in tumor growth and tumor-associated angiogenesis. Lab Invest 87: 189-198, 2007.

16. Rodrigues-Ferreira S, Abdelkarim M, Dillenburg-Pilla P, Luissint AC, di-Tommaso A, Deshayes F, Pontes CL, Molina A, Cagnard N, Letourneur F, et al: Angiotensin II facilitates breast cancer cell migration and metastasis. PLoS One 7: e35667, 2012.

17. Kosugi M, Miyajima A, Kikuchi E, Horiguchi Y and Murai M: Angiotensin II type 1 receptor antagonist candesartan as an angiogenic inhibitor in a xenograft model of bladder cancer. Clin Cancer Res 12: 2888-2893, 2006.

18. Rodrigues-Ferreira S, Morel M, Reis RI, Cormier F, Baud V, Costa-Neto CM and Nahmias C: A novel cellular model to study angiotensin II AT2 receptor function in breast cancer cells. Int J Pept 2012: 745027, 2012.

19. Carl-McGrath S, Ebert MP, Lendeckel U and Röcken C: Expression of the local angiotensin II system in gastric cancer may facilitate lymphatic invasion and nodal spread. Cancer Biol Ther 6: 1218-1226, 2007.

20. Matsuyama M, Funao K, Kuratsukuri K, Tanaka T, Kawahito Y, Sano H, Chargui J, Touraine JL, Yoshimura N and Yoshimura R: Telmisartan inhibits human urological cancer cell growth through early apoptosis. Exp Ther Med 1: 301-306, 2010.
21. Uemura H, Ishiguro H, Nakaigawa N, Nagashima Y, Miyoshi Y, Fujinami K, Sakaguchi A and Kubota Y: Angiotensin II receptor blocker shows antiproliferative activity in prostate cancer cells: A possibility of tyrosine kinase inhibitor of growth factor. Mol Cancer Ther 2: 1139-1147, 2003.

22. Uemura H, Hoshino K and Kubota Y: Role of renin-angiotensin system and antitumor effect of ARB in prostate cancer. Nihon Rinsho 69 (Suppl 5): S155-S159, 2011 (In Japanese).

23. Uemura $\mathrm{H}$ and Kubota $\mathrm{Y}$ : Application of angiotensin II receptor blocker in prostate cancer. Nihon Rinsho 67: 807-811, 2009 (In Japanese).

24. Funao K, Matsuyama M, Kawahito Y, Sano H, Chargui J, Touraine JL, Nakatani T and Yoshimura R: Telmisartan is a potent target for prevention and treatment in human prostate cancer. Oncol Rep 20: 295-300, 2008

25. Burikhanov R, Zhao Y, Goswami A, Qiu S, Schwarze SR and Rangnekar VM: The tumor suppressor Par-4 activates an extrinsic pathway for apoptosis. Cell 138: 377-388, 2009.

26. Okada $\mathrm{H}$ and Mak TW: Pathways of apoptotic and non-apoptotic death in tumour cells. Nat Rev Cancer 4: 592-603, 2004.

27. Kelly GL and Strasser A: The essential role of evasion from cell death in cancer. Adv Cancer Res 111: 39-96, 2011.

28. Kondo Y, Kanzawa T, Sawaya R and Kondo S: The role of autophagy in cancer development and response to therapy. Nat Rev Cancer 5: 726-734, 2005 .

29. Mathew R, Karantza-Wadsworth V and White E: Role of autophagy in cancer. Nat Rev Cancer 7: 961-967, 2007.

30. Kang SJ, Tak JH, Cho JH, Lee HJ and Jung YJ: Stimulation of the endosomal TLR pathway enhances autophagy-induced cell death in radiotherapy of breast cancer. Genes \& Genomics 32: 599-606, 2010.

31. Bose SK, Gibson W, Giri S, Nath N and Donald CD: Angiotensin II up-regulates PAX2 oncogene expression and activity in prostate cancer via the angiotensin II type I receptor. Prostate 69: 1334-1342, 2009.

32. Schweichel JU and Merker HJ: The morphology of various types of cell death in prenatal tissues. Teratology 7: 253-266, 1973.

33. Kroemer G and Levine B: Autophagic cell death: The story of a misnomer. Nat Rev Mol Cell Biol 9: 1004-1010, 2008.

34. Yosypiv IV, Schroeder M and El-Dahr SS: Angiotensin II type 1 receptor-EGF receptor cross-talk regulates ureteric bud branching morphogenesis. J Am Soc Nephrol 17: 1005-1014, 2006.

35. Yang WL, Perillo W, Liou D, Marambaud P and Wang P: AMPK inhibitor compound $\mathrm{C}$ suppresses cell proliferation by induction of apoptosis and autophagy in human colorectal cancer cells. J Surg Oncol 106: 680-688, 2012.

36. Galavotti S, Bartesaghi S, Faccenda D, Shaked-Rabi M, Sanzone S, McEvoy A, Dinsdale D, Condorelli F, Brandner S, Campanella M, et al: The autophagy-associated factors DRAM1 and p62 regulate cell migration and invasion in glioblastoma stem cells. Oncogene 32: 699-712, 2013.

37. Michaud M, Martins I, Sukkurwala AQ, Adjemian S, Ma Y, Pellegatti P, Shen S, Kepp O, Scoazec M, Mignot G, et al: Autophagy-dependent anticancer immune responses induced by chemotherapeutic agents in mice. Science 334: 1573-1577, 2011.

38. Konstam MA, Neaton JD, Dickstein K, Drexler H, Komajda M, Martinez FA, Riegger GA, Malbecq W, Smith RD, Guptha S, et al: Effects of high-dose versus low-dose losartan on clinical outcomes in patients with heart failure (HEAAL study): A randomised, double-blind trial. Lancet 374: 1840-1848, 2009.

39. Abe M, Okada K, Maruyama T, Matsumoto S and Matsumoto K: Blood pressure-lowering and antiproteinuric effect of switching from high-dose angiotensin receptor blockers to normal-dose telmisartan and low-dose hydrochlorothiazide in hypertensive patients with chronic kidney disease. Int J Clin Pharmacol Ther 48: 206-213, 2010.

40. Colegio OR, Chu NQ, Szabo AL, Chu T, Rhebergen AM, Jairam V, Cyrus N, Brokowski CE, Eisenbarth SC, Phillips GM, et al: Functional polarization of tumour-associated macrophages by tumour-derived lactic acid. Nature 513: 559-563, 2014

41. Yang M, Zheng J, Miao Y, Wang Y, Cui W, Guo J, Qiu S, Han Y, Jia L, Li H, et al: Serum-glucocorticoid regulated kinase 1 regulates alternatively activated macrophage polarization contributing to angiotensin II-induced inflammation and cardiac fibrosis. Arterioscler Thromb Vasc Biol 32: 1675-1686, 2012. 